partir de 1967, a raiz de un discurso de inauguración académica titulado "La historia literaria como desafio a la ciencia literaria", pronunciado en dicho año por Hans Robert Jauss en la Universidad de Constanza, surge la llamada estética de la recepción, una corriente destinada a provocar un importantísimo cambio de rumbo en la ciencia literaria contemporánea. La gran aportación de la nueva escuela consiste, fundamentalmente, en el descubrimiento del lector como instancia constitutiva de la obra literaria, a quien, como señala Luis $A$. Acosta, no ha de confundirse con el lector intérprete versado en critica literaria: "El lector que se descubre es el que, por asi decirlo, simplemente lee; el destinatario del mensaje literario, que puede ser sica, contradice una experiencia que muestra, una y otra vez, que no hay una única lectura válida de un mismo texto literario, sino múltiples recepciones distintas. En consecuencia, la estética de la recepción estima imprescindible sustituir la concepción ontológica y esencialista del texto por un nuevo concepto funcional, en el que toda obra sea entendida como una entidad con significado exclusivamente con relación a su recepción por el lector (cfr. Groeben/ Vorderer, 1988, 150). Es decir, la obra literaria ha de ser considerada como un conglomerado de signos sin significado inmersos en una relación dialéctica y dinámica con el lector, gracias a la cual éste genera el significado de aquélla en el acto individual de lectura (cfr. Iser, 1970, 229). La constitu-

\title{
CONSTRUCTIVISMO RADICAL Y ENSEÑANZA DE LA LITERATUIRA
}

también un público espectador" (cfr. 1989, 154155). De este modo, se le abren nuevos horizontes a una investigación literaria que hasta entonces ha centrado su atención, casi exclusivamente, en el estudio de la obra y de su autor.

\section{Manuel Maldonado Alemán Universidad DE SEVILla}

ción de la significación textual es concebida, asi, como el resultado de la interacción de dos factores absolutamente indispensables: el texto y su lector.

La naturaleza del acto de lectura como una acción individual y dinámica de creación de estructura significativa explica El rechazo de la consideración del texto literario como una entidad cerrada, existente con independencia propia y poseedora de significado único e invariable, va a suponer el punto de partida del cambio de perspectiva efectuado por la estética de la recepción. Ese concepto sustancial del texto, propio de la hermenéutica cláque el texto se manifieste, esencialmente, como una entidad polivalente susceptible de provocar en el lector distintos significados. Esta polivalencia aparece motivada por la indeterminación expresada en los espacios vacios que constituyen el texto. El lector, en

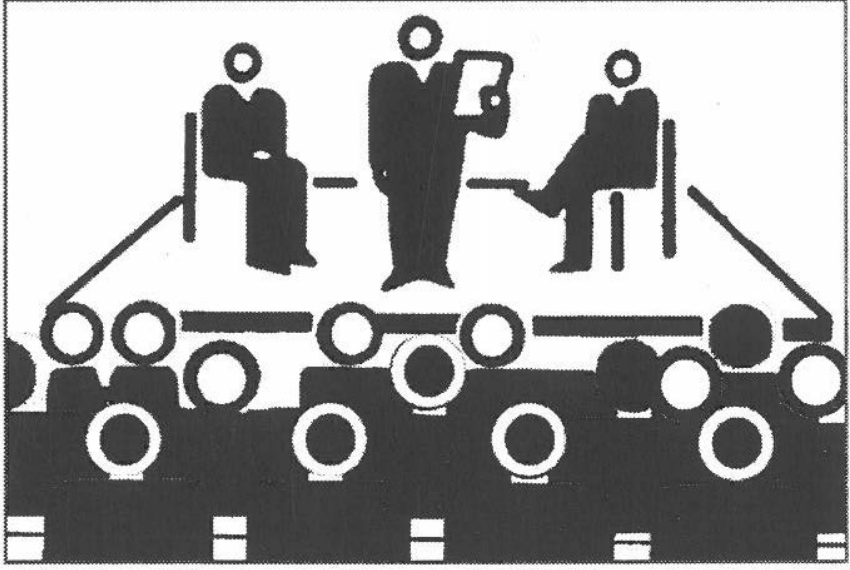


dependencia de factores de indole tanto subjetiva como contextual (experiencias previas, concepciones estéticas, capacidad, expectativas, contexto histórico-social, etc.), determinará y llenará de contenidos específicos, en una actualización concreta, esos espacios vacios; es decir, asignará al texto, en el marco de las posibilidades que éste y sus propios condicionantes o disposiciones le ofrecen, un sentido u otro que será siempre su sentido individual. La concretización activa de la indeterminación textual transformará, de este modo, la materialidad inicial del texto en obra literaria con significado y otorgará al lector una posición privilegiada al convertirlo, en cuanto instancia constitutiva de significado, en cocreador 0 , incluso, en coautor de la obra.
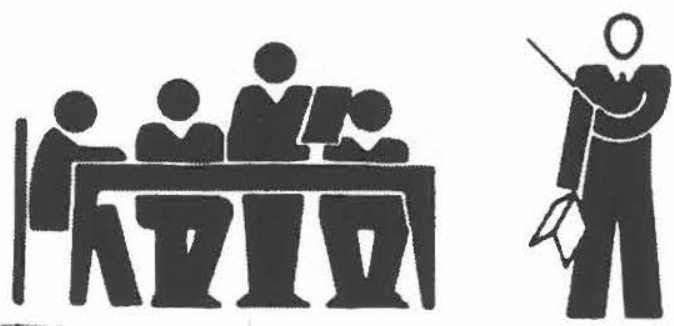

En razón, concretamente, de este peculiar potencial polisemántico de la obra literaria, pero también en consideración a la relativización del significado que de él dimana, el nuevo concepto funcional del texto presenta un marcado carácter constructivista, en el sentido que es el lector, en un proceso de actualización significativa, el llamado a cerrar y concluir activamente la obra que hasta el mismo acto de lectura es abierta e indeterminada.

La estética de la recepción asume, en efecto, este cambio de perspectiva conceptual. Sin embargo, paradójicamente, no sólo elude el desarrollo de un procedimiento metodológico de investigación $y$ estudio de los procesos de recepción coherente con los planteamientos teóricos, sino que, además, su práctica real de interpretación y análisis, al incorporar el constructo teórico del "lector implicito" (cfr. Iser, 1972 y 1976), reincide en los antiguos postulados de la hermenéutica clásica de certeza subjetiva y evidencia. El lector implícito es considerado como la norma contenida en el texto, que dirige su lectura y que posibilita su adecuada recepción (cfr.
Iser, 1972, 8-9, y 1976, 60). Precisamente por ello, dado que es el lector implicito y no el real el determinante de la recepción de la obra, este concepto supone la aceptación de una preestructuración del significado potencial del texto en el mismo texto. Asi pues, la estética de la recepción, ignorando sus propios planteamientos teóricos, acaba asumiendo, de hecho, el concepto inmanente y ontológico del texto, que había intentado superar (cfr. Groeben, 1980, 45-66, y Acosta, 1989, 238-292)

La actitud incoherente de la estética de la recepción hace necesaria una nueva orientación en los estudios crítico-literarios, que no sólo acepte a nivel teórico el concepto funcional del texto, sino que también asuma consecuentemente las implicaciones metodológicas que de él se deriven. Esta nueva orientación ha encontrado su fundamentación en el llamado "constructivismo radical", una concepción que, apoyándose en investigaciones recientes de ciencias como la biología, la cibernética o la psicologia, intenta superar con rigor las múltiples ontologias realistas sin renunciar a la realidad.

El constructivismo radical (no ha de confundirse con el constructivismo filosófico de la Escuela de Erlangen) se fundamenta teóricamente en una concepción constructivista de la cognición, tal como ha sido desarrollada, desde diversos puntos de vista, principalmente por el neurofisiólogo Gerhard Roth, los biólogos Humberto R. Maturana y Francisco ] Varela, el psicólogo Ernst von Glasersfeld (a él se le debe la denominación) y el cibernético Heinz von Foerster.

Un aspecto esencial caracteriza el proceder de la teoría constructivista de la cognición: la sustitución de la cuestión planteada por la epistemología tradicional acerca del qué conocemos, por el problema más complejo del cómo de la realización del conocimiento. Es el proceso cognitivo, con sus efectos y resultados, y no el objeto del conocimiento, lo que realmente ha de ser analizado al determinar el primero la configuración del segundo. La teoria constructivista de la cognición parte del principio de que la percepción de la realidad, como fenómeno que incluye la existencia del objeto, no se origina en los órganos de los sentidos, sino en las regiones especificamente sensoriales del cerebro (cfr. Roth, 1985) 
El cerebro humano, debido a la carencia de acceso directo al mundo exterior, se manifiesta funcionalmente en lo cognitivo como un sistema cerrado, autorreferencial y autoexplicativo, poseedor de un "lenguaje» propio. La conexión con la realidad la realiza el cerebro mediante los órganos receptores. Estos órganos son los encargados de adecuar a las caracteristicas propias del cerebro, esto es, de «traducir:: al lenguaje cerebral de impulsos bioeléctricos, los estímulos procedentes del exterior, que de otra forma no podrian ser registra. dos. El cerebro, al

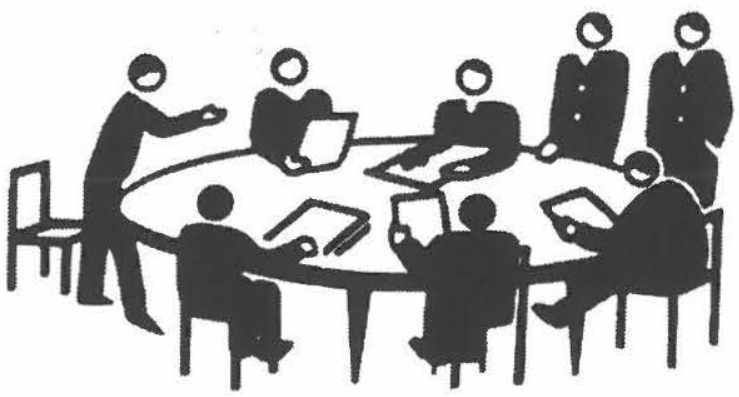

correspondencia con una realidad ontológica. No percibimos las cosas como son, sino como nuestro cerebro las percibe. En definitiva, el cerebro nunca podrá acceder al "Urbild", al arquetipo del modelo de realidad construido por él mismo. Tanto la estructura como la función del cerebro imposibilitan la reproducción de ese mundo real, llegándose cuando más a la construcción dinámica de un mundo de experiencia que, en suma, es nuestro mundo.

El mundo que experimentamos es, por tanto, un mundo cognitivo construido por nosotros mismos, un modelo estructurado y determinado por el observador y su cerebro de acuerdo con sus caracteristicas propias.

El constructivismo radical ha dedicado numerosos estudios precisamente al análisis de la función que el observador desempeña en el proceso cognitivo y a la dilucidación de la organización y estructura de los seres vivos en las que el conocimiento se enraiza. Los resultados de estas investigaciones, desarrolladas ante todo por los biólogos H. R. Maturana yF. J. Varela, configuran lo que ellos han convenido en denominar la "teoria de los sistemas autopoiéticos" (cfr. Maturana, 1982, y Schmidt, 1987).

Según esta teoria, un organismo vivo es un sistema autopoiético, es decir, un sistema autónomo y estructuralmente determinado, organizado de forma autoproductora, autorreguladora y autorreferencial. Mediante su manera de operar un organismo vivo crea de continuo su propia organización. Gracias a la manifestación ciclica de esa organización, el organismo puede mantenerse precisamente con vida, siendo el proceso vital tanto resultado como instrumento de si mismo. La propia organización fija el medio en el que el sistema vivo ha de actuar y al que estructuralmente se puede acoplar. Todas las operaciones del sistema, también las cognitivas, estarán subordinadas al mantenimiento y mejoramiento en ese medio de la autopoiesis, que es, en definitiva, la que garantiza su existencia. De este 
modo, el conocimiento aparece determinado por la forma especifica en la que el ser vivo realiza su autopoiesis. En resumidas cuentas, "lo que vivimos y experimentamos, lo que conocemos y llegamos a saber está necesariamente construido con nuestros propios materiales y sólo se puede explicar de acuerdo con nuestra manera y forma de construir", como recalca E. von Glasersfeld $(1981,35)$.

Los procesos humanos de percepción y conocimiento se caracterizan por estar constituidos tanto por los determinantes biológicos surgidos en el transcurso de la evolución como también por los condicionantes sociales que cada individuo, en forma de tradiciones y convenciones, ha asimilado en su proceso de socialización. Como ya se ha expuesto, en el acto cognitivo el ser humano no reproduce el mundo real; muy al contrario, merced a la continua interacción con su mundo circundante y con otros seres humanos, construye modelos que son aceptados socialmente como realidad. Con la ayuda de esos modelos de realidad socialmente admitidos, el sujeto se orienta y sistematiza sus experiencias.

Los modelos de realidad son ciertamente de indole cognitiva y dependientes del sujeto. No obstante, conviene señalar que ello no implica que la realidad asi construida deba ser necesariamente de carácter subjetivo. El sujeto de la cognición es ante todo un individuo socializado que ha desarrollado sus modelos bajo unas condiciones sociales muy especificas de interacción con otros sujetos. El modelo de realidad surgido de esta interacción, aunque inequívocamente de carácter cognitivo, también presenta una naturaleza social que impide, en suma, la arbitrariedad en su construcción. Aunque los modelos de realidad, al no corresponder con la misma realidad, no pueden ser considerados objetivos, tampoco son subjetivos, sino básicamente intersubjetivos. Lo que normalmente llamamos objetividad es, para el constructivismo radical, esencialmente intersubjetividad, es decir, el consenso en torno a determinados métodos y crite- rios de interacción alcanzado por distintos sujetos gracias a la semejanza de su estructura y proceso de socialización.

Queda descartada la posibilidad de un conocimiento objetivo de la realidad absoluta, tampoco puede admitirse, en consecuencia, la "verdad" como criterio regulador de la actividad cientifica. Los resultados de la investigación cientifica no pueden ser juzgados por su mayor o menor acercamiento a la verdad objetiva, sino, fundamentalmente, en lo que atañe a su grado de utilidad para la vida humana. La efectividad de los conocimientos humanos para garantizar la autopoiesis y el mejoramiento de las condiciones de vida, y no su pretendida verdad, debe constituir el principio regulador de la ciencia (cfr. Schmidt, 1986, 10-11)

La capacidad de interacción consensuada que poseen los seres humanos les permite comunicarse entre si. Esta comunicación no debe entenderse como un intercambio de información, sino como una construcción paralela de información en las regiones cognitivas de los individuos que se comunican. El emisor del mensaje, usando los medios convencionales de comunicación, puede motivar al receptor a poner en funcionamiento su sistema cognitivo. Pero qué operaciones cognitivas éste realiza y qué resultados éstas tendrán, sólo lo puede determinar el propio receptor.

La causa la encontramos en lo anteriormente expuesto: la comunicación aparece unida a un canal que transmite el mensaje a los órganos receptores del oyente o lector. Estos órganos envian el mensaje al cerebro ya traducido a su lenguaje. Pero el mensaje transmitido es en realidad un conglomerado de impulsos eléctricos, y no pensamientos o informaciones. Estos surgen únicamente en las regiones cognitivas del sujeto en cuestión, en absoluta dependencia de sus caracteristicas y condicionantes propios. En términos rigurosos, por consiguiente, no se puede decir que exista una transmisión de información entre receptor y emisor del mensaje.

Conforme a esta concepción constructivista de la comunicación, todo el proceso de recepción literaria adquiere una nueva dimensión. Conceptos como 
referencia, denotación o significado, o bien, operaciones como las de comprensión o interpretación de un texto literario requieren una nueva explicación.

El concepto mismo del texto cambia sustancialmente. El texto ya no es una entidad objetiva y autónoma que se pueda utilizar como referente para demostrar la verdad o falsedad de los juicios que han sido emitidos sobre su sentido. El texto es esencialmente una dimensión física sin significado. La percepción de esa dimensión como texto y la construcción de su correspondiente significado es una actividad exclusiva del lector, que éste realiza siguiendo unas estrategias cognitivas propias. El significado, en definitiva, no es una cualidad autónoma del texto, ni siquiera es el producto de la interacción texto-lector, como defiende la estética de la recepción; es, tan sólo, el resultado de las operaciones cognitivas del lector.

La conceptuación de la comprensión textual como el acto de recoger o reproducir la información que se encuentra supuestamente en la obra es, conforme a lo expresado, una apreciación errónea. La comprensión de un texto literario es un proceso dinámico y complejo de construcción de significado. El lector, siguiendo las pautas establecidas por sus propios conocimientos, expectativas, convenciones literarias, etc., desarrolla una estrategia de lectura determinada que acabará adjudicando al texto un significado concreto de acuerdo con esos condicionantes previos. Qué tipo de significado le asigna al texto, depende de las estrategias de adjudicación empleadas que pueden variar de individuo a individuo. La coincidencia de significados producidos por distintos lectores en torno a un mismo texto se debe atribuir al empleo de estrategias de lectura y convenciones literarias semejantes, pero no a la posibilidad de que hayan reconocido el significado "correcto" en el texto. Este fenómeno se puede dar fundamentalmente entre individuos que, al haber tenido un proceso similar de socialización, disponen de modelos de realidad y, por tanto, de convenciones lingüísticas, literarias, estéticas, etc. afines.

En virtud de lo expuesto, la interpretación de un texto literario no puede concebirse como la consta- tación del sentido "correcto" del texto, o bien, como el descubrimiento de la "verdadera" intención del autor. El supuesto sentido correcto de un texto sólo se podria indagar si existiera una referencia objetiva fuera del ámbito cognitivo del sujeto, que sirviera de medida imparcial de comprobación. La inexistencia de ese marco objetivo de referencia y la falta, por consiguiente, de una relación de legitimación entre texto e interpretación provocan que los criterios de valoración de una interpretación no sean los de verdad o falsedad, sino los de consenso, plausibilidad e innovación, entre otros. Más que de la constatación del supuesto sentido atemporal y único de un texto, la corroboración de una interpretación es consecuencia de una operación de convencimiento social: una interpretación logra finalmente imponerse no porque el texto la legitima y demuestra su "verdad", sino gracias a su aceptación social por consenso. El grado de aceptación de la interpretación dependerá de su conformidad con las necesidades, convenciones y criterios de valoración de una sociedad dada en un momento determinado.

Al margen de las significativas implicaciones que de aqui resultan para el concepto y la función de la literatura en general, el constructivismo radical tiene, además, consecuencias importantes para su enseñanza, que posiblemente nos ayuden a encontrar la dirección en la que podrian resolverse los problemas que a ésta se le plantean.

En consonancia con los planteamientos desarrollados, la concepción didáctica tradicional que centra la enseñanza de la literatura en la transmisión de una interpretación magistral, definitiva y, por supuesto, "correcta" del texto, carece de toda justificación cientifica. Este modelo didáctico, en su afán por sustituir el texto literario por la correspondiente interpretación fijada de antemano, tiene como consecuencia que, en definitiva, los alumnos no apren-

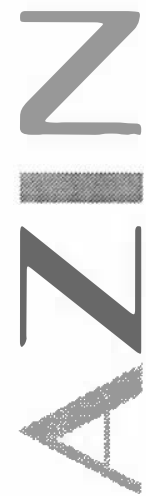




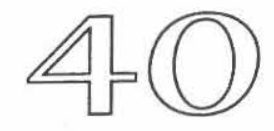

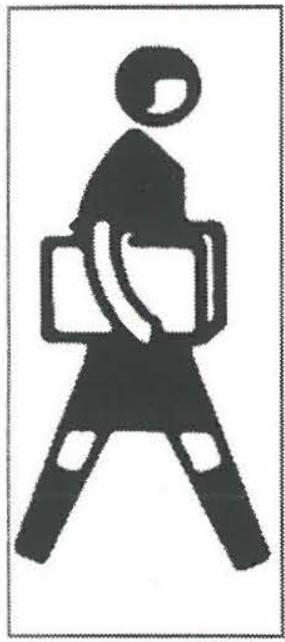

den a leer y comprender el texto, sino más bien la interpretación pertinente. Estos, careciendo de toda motivación, se contentan con la lectura de la interpretación ofrecida y desestiman el propio texto. De esta manera, profesor y alumno ven limitadas sus funciones a las de intérprete activo y receptor pasivo respectivamente, negándose la posibilidad real de una interacción común.

Una estrategia didáctica que acepte la poliinterpretabilidad del texto literario y que tenga en consideración la propia condición subjetiva de los intérpretes debe romper con este umonopolio de la interpretación” y evitar que los esquemas interpretativos de cualquier autoridad literaria sirvan de norma para la comprensión textual de los alumnos. Estos deben tener la posibilidad de desarrollar libremente su disposición para la interpretación literaria en virtud de un modelo didáctico de interacción profesor-alumno y alumno-alumno, que permita una forma de trabajo textual cooperativo y activo, y a la vez solidario con el desarrollo individual del discente.

La interacción colectiva debe mostrar a los alumnos la posibilidad de las diferentes variantes de constitución de significado de un texto literario, de sus distintas formas de lectura; asi como también la utilidad y coherencia de éstas. En consecuencia, no se pretende conseguir, y en absoluto forzar, una interpretación aceptada por todos unánimemente. Fundamentalmente, se debe estimular una interpretación coherente del texto desarrollada por el mismo alumno partiendo de sus posibilidades subjetivas. Esta actitud no impide, sin embargo, que se analicen determinadas interpretaciones «ejemplares" surgidas fuera del ámbito de la interacción; pero siempre que esto ocurra, se han de situar y valorar en su contexto diacrónico y sincrónico.

En suma, la conclusión a extraer de estas reflexiones es la conveniencia de que el alumno se acerque al texto partiendo conscientemente de su propia situación, necesidades, expectativas, deseos, intereses, etc., que reflexione no sólo sobre el texto que se le presenta, sino también sobre sus condicionantes especificos que determinarán, en definitiva, su propia interpretación. Conforme a ello, se pretende evitar una enseñanza de la literatura centrada única y exclusivamente en el texto, o en el peor de los casos tan sólo en una interpretación de él, y se sostiene la necesidad de incluir en el proceso de interpretación la propia «historicidad» del alumno, factor que le obligará a reflexionar sobre su situación y a reconocer y articular sus necesidades.

M.M.A.

\section{BIBLIOGRAFÍA:}

- ACOSTA, L. A., 1989, El lector y la obra. Teoría de la recepción literaria, Madrid, Gredos.

- GLASERSFELD, E. VON, 1981, "Einführung in den radikalen Konstruktivismus", en P. Watzlawick (ed.), Die erfundene Wirklichkeit. Wie wissen wir, was wir zu wissen glauben? Beiträge zum Konstruktivismus, München-Zürich, Piper, 1985, págs. 16-38.

- GROEBEN, N.,1980, Rezeptionsforschung als empinische Literaturwissenschaft. Paradigma- durch Methodendiskussion an Untersuchungsbeispielen, Tübingen, Narr.

- GROEBEN, N./ VORDERER, P., 1988, Leserpsychologie: Lesemotivation - Lektürewirkung, Münster, Aschendorff.

- ISER, W., 1970, Die Appellstruktur der Texte. Unbestimmtheit als Wirkungsbedingung literarischer Prosa, en R. Warning (ed.), Rezeptionsästhetik. Theorie und Praxis, München, Fink, 1988, págs. 228-252.

- ISER, W., 1972, Der implizite Leser. Kommunikationsformen des Romans von Bunyan bis Beckett, München, Fink.

- ISER, W., 1976, Der Akt des Lesens. Theorie ästhetischer Wirkung, München, Fink.

—JAUSS, H. R., 1970, Literaturgeschichte als Provokation, Frankfurt am Main, Suhrkamp

- MATURANA, H. R., 1982, Erkennen: Die Organisation und Verkörperung von Wirklichkeit. Ausgewählte Arbeiten zur biologischen Epistemologie, Braunschweig-Wiesbaden, Vieweg.

— ROTH, G., 1985, «Erkenntnis und Realität. Das reale Gehirn und seine Wirklichkeit», en S. J. Schmidt (ed.), 1987, págs. 229.255

- ROTH, G., 1986, "Selbstorganisation - Selbsterhaltung - Selbstreferentialität: Prinzipien der Organisation der Lebewesen und ihre Fol. gen für die Beziehung zwischen Organismus und Umwelt", en A. Dress y otros (eds.), Selbstorganisation. Die Entstehung von Ordnung in Natur und Gesellschaft,

— München-Zürich, Piper, págs. 149-180

- SCHMIDT, S. J., 1986, Selbstorganisation, Wirklichkeit, Verantwortung. Der wissenschaftliche Konstruktivismus als Erkenntnistheorie und Lebensentwurt, Braunschweig-Wiesbaden, Vieweg.

—SCHMIDT, S. J., 1987, «Der Radikale Konstruktivismus: Ein neues Paradigma im interdisziplinären Diskurs», en S. J. Schmidt (ed.), 1987, págs. 11-88.

- SCHMIDT, S. J. (ed.), 1987, Der Diskurs des Radikalen Konstruktivismus, Frankfurt am Main, Suhrkamp.

- SCHMIDT, S. J. (ed.), 1992, Kognition und Gesellischaft. Der Diskurs des Radikalen Konstruktivismus 2, Frankfurt am Main, Suhrkamp 


\section{Zwei Namen - eine Adresse:}

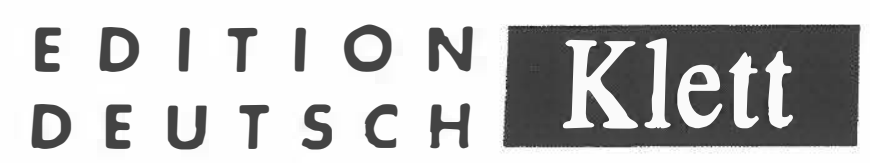

DEUTSCH Rlett

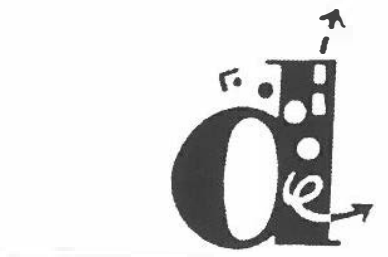

DIFUSION

Centro de Investigación

y Publicaciones de Idiomas s.l.

\section{C/ Bruc,21}

08010 Barcelona

Tel 934122229

Fax 934126660

e-mail: difusion_edites@cambrabcn.es 